\title{
O suicídio na mídia: reflexões para o cuidado em saúde mental
}

\section{The suicide in the media: reflections aiming the mental health care \\ El suicidio en los medios de comunicación: reflexiones para el cuidado en la salud mental}

\author{
Mariana Bteshe ${ }^{1, a}$ \\ marianabteshe@gmail.com | https://orcid.org/oooo-0002-3456-079X \\ ${ }^{1}$ Universidade do Estado do Rio de Janeiro, Faculdade de Ciências Médicas. Rio de Janeiro, RJ, Brasil. \\ a Doutorado em Ciências pela Fundação Oswaldo Cruz.
}

\section{Resumo}

No Brasil, em um curto espaço de tempo, o suicídio passou de um assunto interditado, ou restrito a espaços especializados para um tema em destaque na mídia. O temor de falar sobre o autoextermínio foi substituído por discussões mais abertas e democráticas. Por um lado, estamos diante de uma abertura para falar publicamente sobre o ato suicida, o que, sem dúvida, nos leva a pensar em formas de cuidado mais efetivas. Contudo, ainda nos encontramos sob a regência de uma racionalidade de escala em massa, que regula e normatiza a experiência subjetiva do sofrimento mental. A socialização dos conhecimentos sobre o tema só pode ser feita de forma participativa e dialética. Para isso, é essencial levar em conta os significados dados pelo indivíduo ao lidar com esse tipo de sofrimento, bem como a construção social criada em torno dele.

Palavras-chave: Suicídio; Saúde mental; Assistência integral à saúde; Comunicação em saúde; Informação; Estigma social.

\begin{abstract}
In Brazil, in a short period of time, suicide has gone from a prohibited or restricted subject to specialized spaces for a prominent theme in the media. The fear of talking about self-extermination was replaced by more open and democratic discussions. On the one hand, we are faced with an openness to speak publicly about the suicidal act, which undoubtedly leads us to think of more effective forms of care. However, we are still under the rule of a mass scale rationality, which regulates and normalizes the subjective experience of mental suffering. The socialization of knowledge on the subject can only be done in a
\end{abstract}


participative and dialectical way. For this purpose, it is essential to take into account the meanings given by the individuals when they have to cope with this type of suffering, as well as the social construction created around it.

Keywords: Suicide; Mental health; Comprehensive healthcare; Health communication; Information; Social stigma.

\section{Resumen}

En Brasil, en un corto espacio de tiempo, el suicidio pasó de un asunto prohibido o restringido a espacios especializados para un tema destacado en los medios de comunicación. El temor de hablar sobre el autoexterminio fue sustituido por discusiones más abiertas y democráticas. Por un lado, estamos ante una apertura para hablar públicamente sobre el acto suicida, lo que sin duda nos lleva a pensar en formas de cuidado más efectivas. Sin embargo, todavía nos encontramos bajo la regencia de una racionalidad de escala masiva, que regula y normatiza la experiencia subjetiva del sufrimiento mental. La socialización de los conocimientos sobre el tema sólo puede ser hecha de forma participativa y dialéctica. Para ello, es esencial tener en cuenta los significados dados por el individuo al tratar con ese tipo de sufrimiento, así como la construcción social creada en torno a él.

Palabras clave: Suicídio; Salud mental; Atención integral de salud; Comunicación en salud; Información; Estigma social.

Contribuição dos autores: a autora é responsável pelo texto.

Declaração de conflito de interesses: Este trabalho não apresenta conflito de interesses.

Fontes de financiamento: não houve.

Considerações éticas: não há.

Agradecimento/Contribuições adicionais: não há.

Histórico do artigo: Submetido: 02.set. 2018| Aceito: 03.set.2018 | Publicado: 25.set.2018

Apresentação anterior: não houve.

Licença CC BY-NC atribuição não comercial. Com essa licença é permitido acessar, baixar (download), copiar, imprimir, compartilhar, reutilizar e distribuir os artigos, desde que para uso não comercial e com a citação da fonte, conferindo os devidos créditos de autoria e menção à Reciis. Nesses casos, nenhuma permissão é necessária por parte dos autores ou dos editores. 
É inegável o crescente interesse da mídia, nos últimos dois anos, pelo fenômeno do suicídio e suas diferentes manifestações - pensamentos, gestos, planos e atos. O tema, que permaneceu como um tabu por décadas, ressurgiu como objeto de manchetes e reportagens nas grandes mídias, programas de televisão para o público adolescente, jogos e debates nas mídias sociais digitais. No Brasil, em um curto espaço de tempo, passou de um assunto interditado, pouco falado ou restrito a espaços especializados para um tema em destaque. O temor de falar sobre o autoextermínio foi substituído por discussões mais abertas e democráticas.

Cabe ressaltar que, já em 1996, a Organização das Nações Unidas (ONU) - baseando-se em estatísticas epidemiológicas de diferentes regiões e grupos étnicos que apontavam para um aumento de $65 \%$ nos últimos 40 anos nas taxas de suicídio de jovens na faixa etária de 10 a 24 anos - classificou o suicídio como um grave problema de saúde pública em todo o mundo․ Assim, em 1999, a Organização Mundial de Saúde (OMS) lançou mundialmente o Programa de Prevenção ao Suicídio (Suicide Prevention Program - SUPRE), com o objetivo de integrar as diferentes iniciativas para reduzir a morbidade e mortalidade devido ao comportamento suicida ${ }^{2}$. O Brasil foi o primeiro país da América Latina a aderir à iniciativa da OMS. Em 2005, o Ministério da Saúde instituiu um grupo de trabalho3 para elaborar e implantar uma Estratégia Nacional de Prevenção ao Suicídio, que foi lançada no ano seguinte 4 . Contudo, até dois anos atrás, as principais iniciativas de prevenção, intervenção ou cuidado ainda concentravam-se no seio das universidades e dos grandes centros de pesquisa e em alguns poucos órgãos do governo. A participação ativa da sociedade civil, aqui, era quase nula. Pesquisadores da área e poucos atores sociais estavam comprometidos na produção, divulgação ou vulgarização de conhecimentos sobre o suicídio. Aquilo que era escrito e falado sobre o tema, seja na mídia, na produção literária e em programas de entretenimento, constituía uma produção ainda muito desigual. De fato, 2017 foi o ano em que o suicídio retornou como um tema de interesse público.

Segundo a OMS, um dos pontos de partida para a construção de uma política pública de prevenção de transtornos mentais é a descriminalização e a quebra de tabus, ou seja, a abertura de espaços de fala que não somente acolham de forma cuidadosa as pessoas que passam por essa experiência, mas que as incluam como atores sociais do campo ${ }^{5}$. É notório que a desinformação e o julgamento moral, que geralmente aparecem junto ao comportamento suicida, fazem com que os indivíduos se sintam excluídos socialmente, o que torna o sofrimento ainda maior. A negação e o silenciamento se mostraram mecanismos ineficazes para lidar com a questão.

Quando não existe um espaço, público ou privado, para que esses sentimentos possam ser falados, compartilhados e esclarecidos, a elaboração desse ato se torna muito mais difícil. Em uma pesquisa multicêntrica sobre os fatores que sustentam o processo de luto de familiares e amigos, foram encontradas duas variáveis importantes: a disponibilidade para ajuda social e a abertura na comunidade para falar sobre o assunto ${ }^{6}$. Ambas as variáveis dependem claramente de um processo de desestigmatização do suicídio.

Neste sentido, os estudos da informação e da comunicação desempenham um papel estratégico que é o de dar visibilidade para um grupo até então silenciado, contribuindo para que sejam removidos o estigma e a culpa que os acompanham7 ${ }^{7}$. E além disso, a grande visibilidade midiática dada para a questão descortinou novos desafios e problemas para o campo da saúde mental.

De antemão, é preciso reconhecer que a forma como um tema é abordado nas mídias, sejam elas oficiais ou informais, é sempre determinada culturalmente, resultando de um conjunto de práticas cuja interação constituirá funções sociais que ordenam, normatizam e produzem comportamentos e subjetividades. Soma-se a isso, o fato de que não é uma tarefa fácil falar sobre algo que é desconcertante, que pode ser vivido como uma violência concreta e simbólica. Muito menos reconhecer que os modos como vivemos e nos relacionamos na atualidade podem ter um papel importante sobre um sofrimento pungente, que 
leva alguém a tirar a própria vida. É justamente diante de tantas incertezas, abertamente anunciadas e debatidas, que o suicídio é recoberto pelas mais diferentes compreensões.

Nos últimos trinta anos, o campo da suicidologia tem se desenvolvido rapidamente, aumentando o conhecimento sobre os fatores de proteção e de risco à ocorrência desse agravo. Mesmo em um contexto de rápidas transformações, já temos algumas pistas que nos auxiliam na construção das bases de um cuidado integral em saúde mental. Sabemos, por exemplo, que o fenômeno do suicídio é complexo, que ultrapassa os limites de um único campo do conhecimento, e no qual estão implicados tanto os fatores sociais (credos religiosos, família, política, grupos sociais), como as disposições orgânico-psíquicas, características do ambiente físico e até processos cognitivos de imitação. Pode ser assim entendido como um desfecho de transtornos de saúde, especialmente mentais, porém permanece multicausal ou complexo admitindo inúmeras variáveis dependentes ${ }^{8}$.

Entre os fatores de proteção que podem ser reforçados, encontram-se: reconhecimento do apoio da família, de amigos e de outros relacionamentos significativos; crenças religiosas, culturais e étnicas; envolvimento na comunidade; boa capacidade de comunicação e integração social e acesso aos serviços e cuidados de saúde mental. Na literatura especializada, destaca-se também a busca do reconhecimento de fatores de risco que tendem a tornar as pessoas mais vulneráveis ao suicídio. Preditores de comportamento suicida e fatores de risco incluem: um histórico de tentativas de suicídio anteriores, algumas variáveis demográficas, sintomas clínicos e questões relacionadas com a assistência médica e suporte social. Uma hipótese que tem recebido especial destaque na literatura científica é a combinação de fatores como: sinais do espectro depressivo, personalidade impulsiva, uso de substâncias psicoativas, ambivalência, sensação de solidão e a falta de suporte social ${ }^{9}$.

De fato, a identificação das variáveis demográficas e dos ditos 'grupos de risco' tem tido um papel importante para a avaliação na clínica e na gestão do risco de suicídio. Ao mesmo tempo, nos deparamos com uma divulgação científica incessante desses dados epidemiológicos - fala-se dos números de suicídios em anos, meses, minutos e dias - sem se dar ao trabalho de tecer reflexões sobre os efeitos dessas informações para o grupo de pessoas que foram afetadas diretamente por um suicídio, os chamados sobreviventes e os próprios indivíduos que estão passando por uma vivência de intensa desesperança.

Se, por muito tempo, o suicídio em algumas culturas pôde ser compreendido como um ato de liberdade, autonomia e controle sobre a própria vida, hoje, frequentemente, o ato suicida aparece associado à presença de transtornos mentais, a um discurso de risco que acaba, quase sempre, por normatizar a experiência subjetiva de sofrimento. Em determinados meios, sobretudo naqueles orientados pelo discurso médico, associar o autoextermínio à possibilidade de escolha é incorrer em um grave erro. O imperativo de evitar novas mortes acabou se sobrepondo a toda e qualquer tentativa de compreensão da urgência subjetiva que pode acompanhar um suicídio.

Esse é o preço que pagamos, quando na atualidade o sofrimento psíquico sai da esfera da intimidade e ganha um reconhecimento social no espaço público. Dito de outro modo, estamos diante de uma abertura para falar publicamente sobre o ato suicida, o que, sem dúvida, nos leva a pensar em formas de cuidado mais efetivas. Inúmeros estudos comprovam que países como Estados Unidos, Austrália, Inglaterra, Japão e Suécia, que investiram em planos de prevenção e controle do suicídio a partir de dados epidemiológicos sobre os fatores de risco e de proteção, conseguiram diminuir drasticamente os índices nacionais de suicídio $^{10}$. Contudo, ainda nos encontramos sob a regência de uma racionalidade de escala em massa, que regula e normatiza a experiência subjetiva do sofrimento. Mais ainda, o discurso inexorável de prevenção e de valorização da vida, que visa salvar ou curar a todo custo, traz quase sempre associado um tom de responsabilização dos sobreviventes e de inadequação das pessoas que não se identificam com essa mensagem. E, evidentemente, as práticas de comunicação e de informação são um elemento importante nesse processo de controle e regulação da saúde e da vida. 
É inegável que o suicídio é um problema de saúde pública. O que questionamos neste texto são as formas como a mobilização social, política e cultural em torno desse fenômeno vêm se dando e quais são os efeitos desses discursos. Um adolescente pode verbalizar um sentimento de desesperança e de não pertencimento, quando o discurso hegemônico afirma categoricamente que não suportar as vicissitudes da vida é uma falta de habilidade social, que é característica de uma geração mais fragilizada? Ou quando as mídias dão pouco espaço para os debates sobre os determinantes sociais que podem estar presentes como precipitantes do comportamento suicida, tais como: a crise econômica; o uso indiscriminado de agrotóxicos; o isolamento social; entre outros?

Ainda temos muito o que caminhar para chegarmos a uma redefinição das concepções sobre o suicídio. Um primeiro passo foi dado, libertando-o do ideário de que este assunto não deve ser falado publicamente. Contudo, a socialização dos conhecimentos sobre o tema só pode ser feita de forma participativa e dialética. Para isso, é essencial levar em conta os significados dados pelo indivíduo ao lidar com esse tipo de sofrimento, bem como a construção social criada em torno dele. É igualmente importante envolver a comunidade e considerar suas características próprias. Não basta a repetição de dados epidemiológicos descontextualizados ou alertas nos moldes de mitos e verdades. Melhorar a prevenção do suicídio e as ações de posvenção exige uma maior compreensão de como e por que as pessoas decidem acabar com suas próprias vidas em diferentes contextos. A construção de um plano de cuidado implica em pensar no caso a caso, conhecer e escutar as diferentes histórias e narrativas que constituem aquele sujeito ou grupo social. A proposta é que aqueles que buscam ajuda, ou que já são usuários de serviços de saúde mental, ou que se consideram em risco precisam efetivamente ser acolhidos e escutados para além de qualquer rótulo estigmatizante ou esquemas de compreensão do suicídio. Falar abertamente não basta. É preciso investir na criação e manutenção de espaços de acolhimento, sobretudo, no Sistema Único de Saúde (SUS). Não pretendemos esgotar aqui essa discussão, mas identificar as questões e os problemas que surgem quando lançamos luz sobre um tema tão controverso, sobretudo, no âmbito do cuidado em saúde mental. 


\section{Referências}

1. United Nations. Prevention of suicide guidelines for the formulation and implementation of national strategies. New York: United Nations; 1996.

2. World Health Organization. Figures and facts about suicide. Geneve: WHO; 1999.

3. Brasil. Portaria no 2.542, de 22 de dezembro de 2005. Institui Grupo de Trabalho com o objetivo de elaborar e implantar a Estratégia Nacional de Prevenção ao Suicídio [Internet]. Diário Oficial da República Federativa do Brasil. Brasília (DF): Ministério da Saúde, 22 dez. 2005 [citado em 02 set. 2018]. Disponível em: http://bvsms.saude.gov.br/bvs/saudelegis/gm/2005/prt2542 2212 2005.html

4. Brasil. Portaria no 1.876, de 14 de agosto de 2006, Institui Diretrizes Nacionais para Prevenção do Suicídio, a ser implantadas em todas as unidades federadas, respeitadas as competências das três esferas de gestão. Brasília (DF): Ministério da Saúde, 14 ago. 2006 [citado em 02 set. 2018]. Disponível

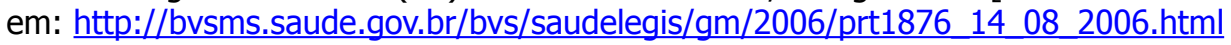

5. World Health Organization. Prevention of mental disorders: effective interventions and policy options: summary report. Geneve: WHO; 2002.

6. Grad OT, Clark S, Dyregrov, Andriessen K. What helps and what hinders the process of surviving the suicide of somebody close? Crisis [Internet]. 2004 [citado em 02 set. 2018];25(3):134-139. doi: https:// doi.org/10.1027/0227-5910.25.3.134

7. Tadros, G; Jolley D. The stigma of suicide. The British Journal of Psychiatry. 2001 [citado em 02 set. 2018];179(2):178. doi: https://doi.org/10.1192/bjp.179.2.178

8. World Health Organization. Public health action for the prevention of suicide. Geneve: WHO; 2012.

9. Botega NJ. Crise suicida: avaliação e manejo. Porto Alegre: Artmed; 2015.

10. Beautrais A. Suicide prevention strategies 2006. AeJAMH [Internet]. 2006 [citado em 02 set. 2018];5(1):1-6. doi: https://doi.org/10.5172/jamh.5.1.16 